\title{
Invasive Ductal Carcinoma of the Breast in an Elderly Male Veteran with Solid Papillary Growth Pattern: A Case Report
}

Fidelis O. Ojevwe, MD, PharmD ${ }^{1 *}$, Kegan Jessamy, MD¹, Cindy D. Ojevwe, BS ${ }^{2}$, Naili Ma, MD ${ }^{4}$, Amit Bhardwaj, MD ${ }^{1}$, Namita Sharma, MD $^{5}$ and Semana Zaidi, MD ${ }^{1}$

${ }^{1}$ Department of Medicine, SUNY Upstate Medical University, Syracuse, NY, USA

${ }^{2}$ SUNY Upstate Medical School, Syracuse, NY, USA

${ }^{3}$ Department of Medicine, Veteran Medical Center, Syracuse, NY, USA

${ }^{4}$ Department of Pathology, Veteran Medical Center, Syracuse, NY, USA

${ }^{5}$ Department of Medicine, Hematology/Oncology Division, SUNY Upstate Medical University, Syracuse, NY, USA

\begin{abstract}
Breast cancer in men is rare but carries a poor prognosis. The incidence is increasing but remains less than $1 \%$ of all cancer among American men and less than $0.1 \%$ mortality. Here, we report an 83 -year-old Caucasian male Veteran with high-grade invasive ductal carcinoma of the left breast with solid papillary growth with underlying hematoma after sustaining trauma to the left anterior chest wall. There are no reported cases of this type of growth pattern in the literature.
\end{abstract}

Keywords: Breast cancer; Caucasian male; Solid papillary growth; Hematoma

\section{Background}

Male breast cancer is a rare malignancy that accounts for approximately $1 \%$ of all malignancies in men $[1,2]$. The approximated incidence is 1 in 100,000 and accounts for less than $0.1 \%$ in cancerrelated deaths in men [1]. Among the histologic types, invasive ductal carcinoma is the most prevalent breast cancer in males, with incidence varying from 65 to $95 \%$ [2].

Male breast cancer has unimodal age-frequency distribution with peak incidence at age 71 but frequently seen after the age of 60 [13]. Conversely, women breast cancer has a bimodal age distribution with early-onset and late-onset peak incidences at 52 and 72 years old, respectively [2]. The median age of diagnosis in men is 65 years old, thus men are diagnosed with breast cancer later than women by 5 to 10 years $[2,4]$.

\section{Case Presentation}

An 83-year-old male with past medical history of hypertension and Deep Venous Thrombosis being managed on metoprolol and Coumadin, respectively, presented to Syracuse Veteran Hospital (VAH) with left nipple bleeding of two days duration. Patient endorsed 2 months prior to presenting to Hospital he sustained mechanical fall resulting in blunt injury to left anterior chest wall area. Patient noted some bruising with ecchymosis around his left breast and nipple. Patient subsequently noticed swelling and enlarging mass around the left nipple that he attributed to hematoma from the fall. Patient did not seek medical attention until the day of presentation to the VAH when he noticed significant bleeding from the left nipple. On further inquiry patient reported 40 pounds of unintentional weight loss over the past 6 months. Family history is unremarkable for cancer or coagulopathy. Social history is significant for long history of cigarette smoking, occasional alcohol use, and Korean War veteran. Review of system was unremarkable except for aforementioned. On physical examination revealed well-developed but with evidence of weigh loss. On examination of the chest, there was significant overlying ecchymosis and skin necrosis eroding through the nipple with bleeding and a large necrotic left breast mass. On laboratory, comprehensive metabolic panel and complete blood count were unremarkable except for mild anemia with hemoglobin of $11.5 \mathrm{~g} / \mathrm{dL}$ and supratherapeutic International Normalized Ratio (INR) of 4.3.
CT thorax showed a large subcutaneous mass measuring approximately $9.6 \times 5.6 \mathrm{~cm}$ with central heterogeneous necrosis in the left anterolateral chest (Figure 1a and $1 \mathrm{~b}$ ). Surgery was consulted and patient underwent Toilet mastectomy of the left breast with biopsy. Given the skin involvement and complete ulceration and destruction of nipple areola complex, it was determined that palliative procedure is done rather than oncological procedure. Thus, there was no reason to perform an axillary lymph node dissection. Gross examination of surgical specimen shows a tumor mass $(3.3 \mathrm{~cm}$ in greatest dimension) with extensive skin ulceration due to tumor invasion and margin

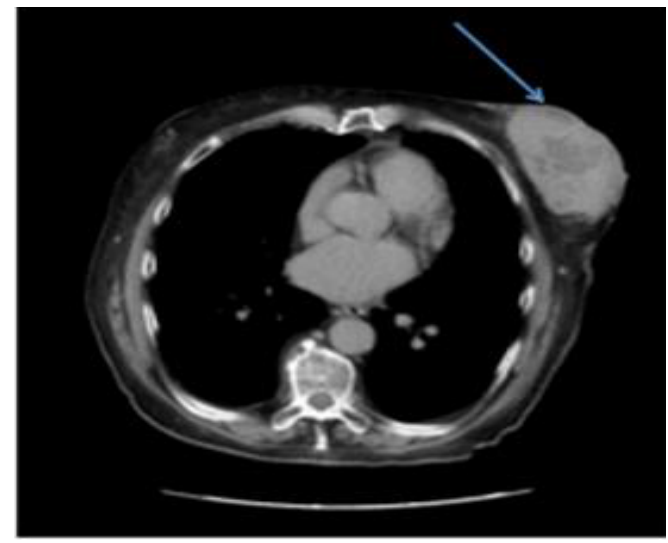

Figure 1a: Oblique view of CT Scan of the thorax with contrast showing large breast mass in the subcutaneous tissue of the left anterolateral chest measuring approximately $9.6 \times 5.6 \mathrm{~cm}$.

*Corresponding author: Fidelis Ojevwe, MD, PharmD, Department of Medicine, SUNY Upstate Medical University, Syracuse, NY, USA, Tel: 315-464-4506; Fax 315-464-4485; E-mail: ojevwef@upstate.edu

Received September 04, 2015; Accepted October 17, 2015; Published October 24, 2015

Citation: Ojevwe FO, Jessamy K, Ojevwe CD, Ma N, Sharma N, et al. (2015) Invasive Ductal Carcinoma of the Breast in an Elderly Male Veteran with Solid Papillary Growth Pattern: A Case Report. J Clin Case Rep 5: 615. doi:10.4172/21657920.1000615

Copyright: (c 2015 Ojevwe FO, et al. This is an open-access article distributed under the terms of the Creative Commons Attribution License, which permits unrestricted use, distribution, and reproduction in any medium, provided the original author and source are credited. 
involvement. Morphological evaluation demonstrates an invasive ductal carcinoma with unusual solid papillary growth pattern, extensive necrosis and skin involvement (Figure 2). Immunohistochemical analysis showed positive cytokeratin AE1/AE3 and GATA3 (Figure 3), and negative ER and PR for neuroendocrine markers (chromogranin and synaptophysin). With these findings and patient's presentation, the tumor was staged T4NxMx.

\section{Discussion}

It is estimated that about $42 \%$ of breast cancer in men are diagnosed in stage III or IV and this may be attributed to men not seeking medical attention for breast masses as quickly as women [2]. In addition, the tumor is usually closer to the skin in males with increased likelihood of infiltration of the skin [2]. These characteristic features were seen in our elderly patient who likely attributed his breast mass to swelling from his traumatic fall from few months back and did not seek medical

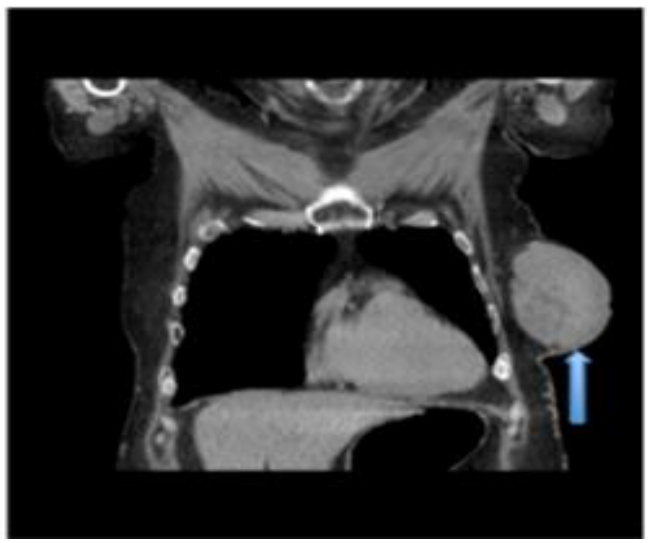

Figure 1b: Coronal view of CT Scan of the thorax with contrast demonstrating a large breast mass, $9.6 \times 5.6 \mathrm{~cm}$, in the left anterolateral chest.
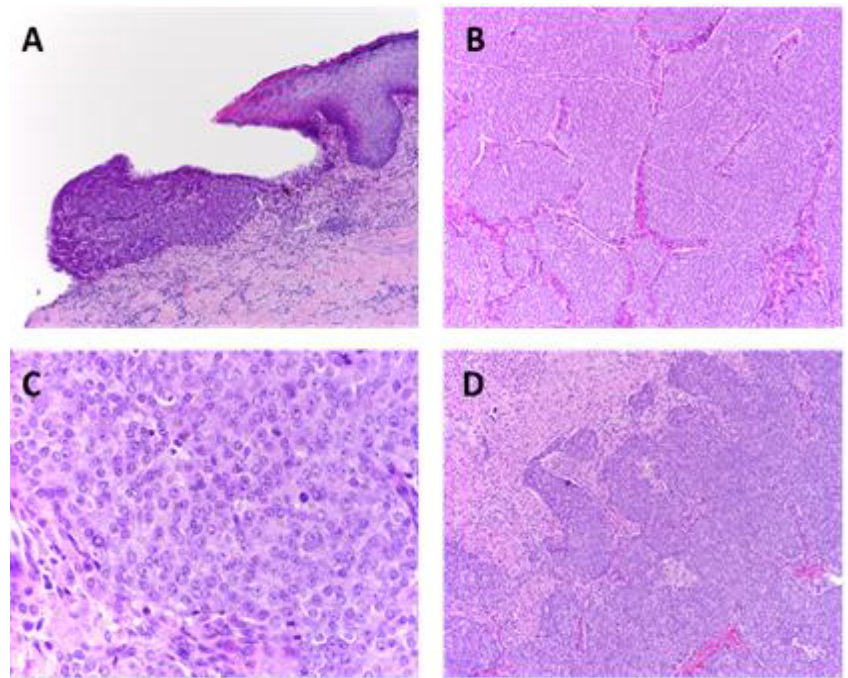

Figure 2: Histological sections stained by hemotoxylin and eosin. (A). Ulcerated skin invaded by the tumor cells (with magnification $10 \mathrm{X}$ ). (B). The section shows the unusual morphology of invasive ductal carcinoma of breast with solid papillary/nesting growth pattern (with magnification $10 \mathrm{X}$ ). (C). Higher magnification of Figure 2B showing tumor cells with uniformly atypical cytology and frequent mitoses (with magnification $40 \mathrm{X}$ ). (D). Tumor tissue showing prominent necrosis (with magnification $10 \mathrm{X}$ ).

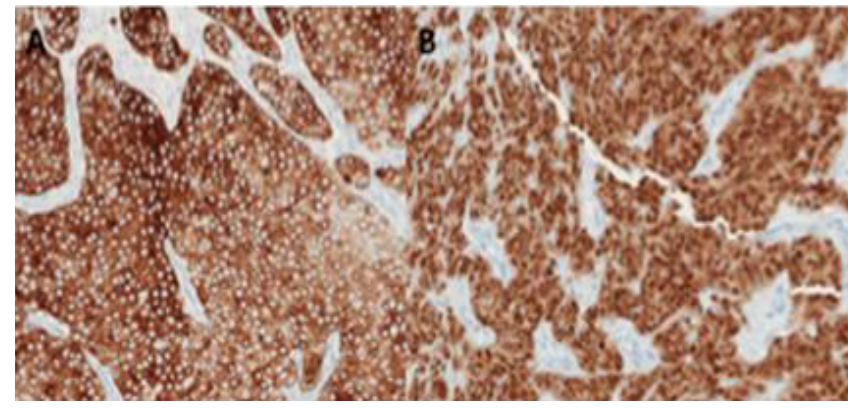

Figure 3: Immunohistochemical analysis showed positive cytokeratin AE1/ AE3 $(A)$ and GATA3 (B) with magnification X30.

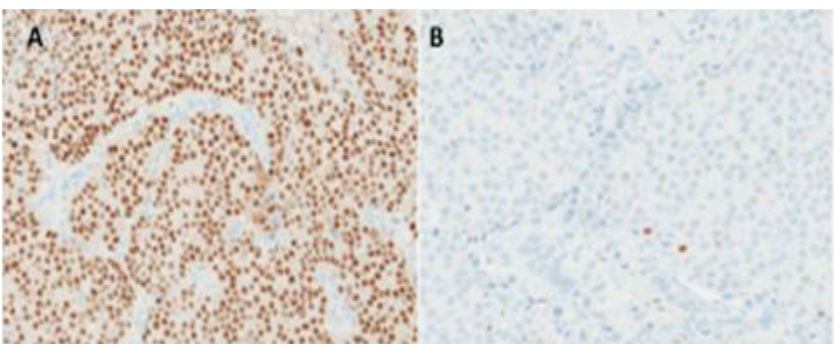

Figure 4: Immunohistochemical analysis with chromogranin and synaptophysin showing negative ER (picture A) and PR (picture B) for neuroendocrine markers.

attention and now presented with necrotic skin with erosion of the nipple.

The etiology of male breast cancer is not well known compared to female breast cancer, but there are several known risk factors that have been implicated which include both genetic and congenital, prior radiation exposure, alterations of the estrogen-testosterone ratio, and occupational hazard $[5,6]$. Of all the known etiologies, the greatest risk factor is concomitant Klinefelter's syndrome [6]. There is 50-fold increased risk developing breast cancer with this syndrome [6]. Our patient did not have any of these risk factors.

The different histologic types of carcinoma identified in female breast cancer have been seen in male, but the most common histologic finding is invasive ductal carcinoma that makes up approximately $90 \%$ $[5,6]$. An important pathologic characteristic of male breast cancer is higher rate of hormone receptor expression compared to with female counterparts. It is estimated that about $90 \%$ of male breast cancer express estrogen-receptor positivity and $80 \%$ express progesteronereceptor positivity [6,7]; this is true in our patient. The treatment modality is dependent on histologic type of cancer as well as the degree of spread of the disease at the time of diagnosis [5]. Patients presenting with nonmetastatic disease, the current recommended treatment modality is modified radical mastectomy with axillary lymph node dissection [6,7]. Our patient underwent Toilet mastectomy due to extensive skin involvement. Since about $90 \%$ of patients are estrogenreceptor positive, tamoxifen is standard adjuvant therapy [6,7]. Many retrospective studies have shown improved survival rates among patients who were treated tamoxifen versus those who did not receive hormonal therapy [8].

\section{Conclusion}

The incidence of male breast cancer is increasing but still remains 
Citation: Ojevwe FO, Jessamy K, Ojevwe CD, Ma N, Sharma N, et al. (2015) Invasive Ductal Carcinoma of the Breast in an Elderly Male Veteran with Solid Papillary Growth Pattern: A Case Report. J Clin Case Rep 5: 615. doi:10.4172/2165-7920.1000615

less than $1 \%$ of all cancer in male. Invasive ductal carcinoma is the most common histologic type among breast cancer in male. Although, the average age of breast cancer in male is after 60 years of age and peaks at age of 71 , there are very few cases of male patients presenting with breast cancer after age of 80 . Our patient presented at age 83 with significant skin involvement and denied any significant family history and any risk factors previous discussed. Our patient underwent staging to determine the extent of his disease and was found to have advance disease due to complete erosion of areola. Our patient is another classic example of a male presenting late at the time of diagnosis. Thus, more awareness is needed to reduce the incidence of late presentation. Since tumor cells are ER and PR positive and Her-2 neu negative, patient was started on Tamoxifen $20 \mathrm{mg}$ po daily.

\section{References}

1. Landero J, Touloei K, Glick BP (2012) Invasive Ductal Breast Carcinoma Underneath a Lipoma in a Male Patient. J Clin Aesthet Dermatol 5: 33-37.
2. Madeira M, Mattar A, Gebrim L (2011) A case report of male breast cancer in a very young patient: what is changing? World Journal Of Surgical Oncology 9: 16.

3. Harlan LC, Zujewski JA, Goodman MT (2010) Breast cancer in men in the United States: a population-based study of diagnosis, treatment, and survival. Cancer 116: 3558-3568.

4. Giordano SH, Cohen DS, Buzdar AU (2004) Breast carcinoma in men: a population-based study. Cancer 101: 51-57.

5. Barry S, Ha KY, Laurie L (2012) Carcinoma of the Breast in Men. Proc 25: 367-668.

6. Ahmad R, Lewis S, Maharaj D (2010) A male patient from the West Indies with invasive ductal carcinoma in the right breast: A case report and literature review. Gender Med 7: 179-183.

7. Patten DK, Sharifi LK, Fazel M (2013) New approaches in the Management of Male Breast Cancer.Clin Breast Can 13: 309-314.

8. Zahir MN, Minhas K (2014) Pleomorphic lobular carcinoma of the male breast with axillary lymph node involvement: a case report and review of literature. BMC Clin Path 14: 16. 